\title{
BMJ Open Retrospective analysis of characteristics associated with higher-value radiotherapy episodes of care for bone metastases in Medicare fee-for-service beneficiaries
}

\author{
Deborah Marshall (D , ${ }^{1}$ Melissa D Aldridge ${ }^{2}$ Kavita Dharmarajan ${ }^{1,2}$
}

To cite: Marshall D, Aldridge MD, Dharmarajan K. Retrospective analysis of characteristics associated with higher-value radiotherapy episodes of care for bone metastases in Medicare fee-forservice beneficiaries. BMJ Open 2021;11:e049009. doi:10.1136/ bmjopen-2021-049009

- Prepublication history for this paper is available online. To view these files, please visit the journal online (http://dx.doi org/10.1136/bmjopen-2021 049009).

This work was presented in part at the AcademyHealth National Health Policy Conference, Washington, DC, 10 February 2020-11 February 2020.

Received 13 January 2021 Accepted 23 September 2021

Check for updates

(c) Author(s) (or their employer(s)) 2021. Re-use permitted under CC BY-NC. No commercial re-use. See rights and permissions. Published by BMJ.

'Department of Radiation Oncology, Icahn School of Medicine at Mount Sinai, New York, New York, USA

${ }^{2}$ Department of Geriatrics and Palliative Medicine, Icahn School of Medicine at Mount Sinai, New York, New York, USA

\section{Correspondence to}

Dr Deborah Marshall;

deborah.marshall@mountsinai. org

\section{ABSTRACT}

Objectives The Centers for Medicare \& Medicaid Services' newly enacted Radiation Oncology Model ('R0 Model') was designed to test the cost-saving potential of prospective episode-based payments for radiation treatment for 17 cancer diagnoses by encouraging highvalue care and more efficient care delivery. For bone metastases, evidence supports the use of higher-value, shorter courses of radiation ( $\leq 10$ fractions). Our goal was to determine the prevalence of short radiation courses ( $\leq 10$ fractions) for bone metastases and the setting, treatment and patient characteristics associated with such courses and their expenditures.

Design Using the RO Model episode file, we evaluated receipt of $\leq 10$ fractions of radiotherapy for bone metastases and expenditures by treatment setting for Medicare fee-for-service beneficiaries during calendar years 2015-2017.

Using unadjusted and adjusted regression models, we determined predictors of receipt of $\leq 10$ fractions and expenditures. Multivariable models adjusted for treatment and patient characteristics.

Results There were 48810 episodes for bone metastases during the period. A majority of episodes for $\leq 10$ fractions occurred in hospital-outpatient settings $(62.8 \%$ $(\mathrm{N}=22715))$. After adjusting for treatment and patient factors, hospital-outpatient treatment setting remained a significant predictor of receiving $\leq 10$ fractions (adjusted OR 2.03 (95\% Cl 1.95, 2.12; $p<0.001$ ) vs free-standing). The greatest adjusted contributors to total expenditures were number of fractions (US\$-3424 (95\% CI US\$-3412 to US\$-3435) for $\leq 10$ fractions vs $>10 ; p<0.001)$ and treatment type (including US\$7716 (95\% CI US\$7424 to US\$8018) for intensity modulated radiation therapy vs conventional external beam; $p<0.001$ ).

Conclusions A measurable performance gap exists for delivery of higher-value bone metastases radiotherapy under an episode-based model, associated with increased expenditures. The RO Model may succeed in improving the value of bone metastases radiation. Increasing the capacity of free-standing centres to implement palliativefocused services may improve the ability of these practices to succeed under the RO Model.

\section{INTRODUCTION}

Under current Centers for Medicare \& Medicaid Services (CMS) policies, radiation therapy practices are reimbursed in large
Strengths and limitations of this study

- For bone metastases, evidence supports highervalue, shorter courses of radiotherapy.

- The Centers for Medicare \& Medicaid Services' Radiation Oncology (R0) Model may increase higher-value care for bone metastases.

- Evaluation of potential performance gaps in R0 Model-defined bone metastases episodes help to better understand the potential for increasing value and cost-savings under the RO Model.

- Lack of detailed patient characteristics limits this study.

part on a fee-for-service basis per fraction of radiation delivered. CMS' established the Radiation Oncology Model ${ }^{1}$ ('RO Model'), beginning on 1 January 2022, designed to test the cost-saving potential of prospective episode-based payments for radiation treatment for 16 cancer diagnoses to furnish more high-value, patient-centric care. CMS points to bone metastases radiotherapy data to support the rationale for the RO Model, stating that 'modifying payment under an episode payment model could change the incentives and encourage physicians to pick higher-value modalities and furnish fewer fractions, where appropriate'. ${ }^{2}$ Substantial evidence supports the treatment of certain bone metastases with shorter treatment schedules. ${ }^{3-7}$ Therefore, the proposed model may shift incentives in the treatment of bone metastases towards shorter ( $\leq 10$ fractions) and less complex but equally efficacious ${ }^{8}$ courses of radiation, resulting in more efficient care delivery, higher-value care and better patient outcomes.

In contrast, the most recent CMS effort to improve the value of palliative radiation for bone metastases, through the implementation of a process quality measure under the Quality Payment Programme, proved overly 
complex and National Quality Foundation endorsement was no longer sought. ${ }^{9}$ The quality measure for radiation of bone metastases was felt to be too prescriptive in requiring a certain number of fractions, too complex to capture through billing and claims data, and not flexible enough to allow for changes in the plan of care which occurs frequently in patients with advanced cancer who often develop disease progression, symptom changes or enrol in hospice thus preventing further receipt of radiation. ${ }^{10}$ Accordingly, much of the Hospital Compare data that was gathered as part of this programme are incomplete or unavailable for the measure with only of 827 (17\%) of 4767 hospitals reporting. Although, in those practices who did gather Quality Payment Programme data on palliative radiation for bone metastases, the national average score for receipt of higher-quality bone metastases radiation for participating hospitals was $89 \%$ in $2018 .^{11}$

An episode-based approach, as included in the RO Model, was developed in order to provide a more reasonable and effective approach to both measure the value and quality of care and provide an opportunity to decrease costs associated with bone metastases radiation, which we explore in this article. Specifically, we sought to determine whether available data captured in the CMS-defined 'episodes of care' included identifiable differences in the inclusion of higher-value radiotherapy for bone metastases, thus providing an opportunity for practices to increase value of care and ensure cost-savings for the programme and their practice. Furthermore, we sought to understand the specific characteristics of radiation oncology practices that could benefit from resources that aid the development of palliative radiation programmes, given that there will likely be great interest in effective ways to improve the value of radiotherapy care as the RO Model is implemented. Palliative RT programmes have been shown to nearly double the utilisation of shorter courses of radiation while maintaining patient-centred outcomes and creating substantial healthrelated cost savings. ${ }^{12}$ However, such programmes are not yet commonplace in radiation oncology practices nationwide.

Therefore, the goal of this study was to evaluate CMSdefined 'episodes of care' to determine the prevalence of higher-value, guideline-consistent radiation courses $(\leq 10$ fractions) for bone metastases as well as the treatment, setting, patient characteristics and expenditures associated with such courses to better understand the potential for increasing value and cost savings under the RO Model.

\section{MATERIALS AND METHODS}

We analysed the RO model episode file, containing data on episodes of radiation treatment for Medicare fee-forservice beneficiaries during calendar years 2015-2017 that would qualify for the RO model ${ }^{13}$ by treatment setting. Treatment settings included hospital-outpatient departments or free-standing centres. Detailed definitions of episodes are defined in the CMS documentation $^{13}$; briefly, episodes were defined as having a cancer diagnosis code and treatment planning and delivery codes, with at least two bone metastases International Classification of Disease (ICD) codes (198.5x; C79.5x) occurring within 30 days and one radiation treatment delivery occurring within 28 days of the triggering planning service. Primary cancer type was not a variable captured in the dataset thus was unavailable. The episode captured all radiotherapy services (treatment consultation, treatment planning, technical preparation and special services (simulation), treatment delivery and treatment management, see reference for radiotherapy services codes ${ }^{13}$ within 90 days from the initial treatment planning service. Expenditures included combined professional and technical fees, and were adjusted to 2017 dollars and winsorised (1st and 99th percentiles). ${ }^{14}$ Treatment types included conventional external beam radiation therapy, intensity modulated radiation therapy (IMRT), stereotactic radiosurgery/stereotactic body radiotherapy (SRS/SBRT) and other treatment types (proton therapy, brachytherapy and intraoperative radiotherapy). Chemotherapy and major procedures occurring in the 90 days prior to or during the episode were also identified ${ }^{13}$ as covariables.

Our primary outcome was receipt of $\leq 10$ fractions, an indicator of higher-value radiation therapy. ${ }^{6}$ We also evaluated a second value indicator, treatment complexity, by examining receipt of conventional external beam radiation versus more expensive modalities such as IMRT and episode expenditures.

First, we assessed differences in treatment and patient characteristics and treatment setting by receipt of $\leq 10$ fractions compared with $>10$ fractions using $\chi^{2}$ tests. Next, we evaluated unadjusted rates of receiving $\leq 10$ fractions, by setting, treatment and patient characteristics. We then fit a multivariable logistic regression model to determine if treatment setting was an independent predictor of receiving $\leq 10$ fractions, adjusting for treatment and patient variables. Treatment and patient variables adjusted for in the multivariable models included patient age group $(<65,65-74,75-84,85+)$, patient sex (male/female), major procedure within 90 days (yes/no) and receipt of chemotherapy within 90 days (yes/no). Variables excluded from the multivariable models were modality (such as SBRT) and death during the episode as these variables would potentially introduce instability into the model due to the number of fractions. Finally, we evaluated unadjusted expenditures using a generalised linear model (gamma distribution with log-link) by setting, treatment and patient characteristics. We then fit a multivariable model of expenditures by setting, adjusting for treatment and patient variables to estimate the independent contributors to differences in expenditures. A twotailed $\mathrm{p}<0.05$ was considered significant. Analyses were performed using R (V.3.6.1). 
Table 1 Characteristics of radiation oncology bone metastases episodes and unadjusted and adjusted analysis of receipt of 10 or fewer fractions of radiation for bone metastases

\begin{tabular}{|c|c|c|c|c|}
\hline & Total, N (\%) & $>10$ fractions, $\mathrm{N}(\%)$ & $\leq 10$ fractions, $\mathrm{N}(\%)$ & P value \\
\hline Overall & $48810(100.0)$ & $12611(25.8)$ & $36199(74.2)$ & \\
\hline Treatment setting & & & & $<0.001$ \\
\hline Freestanding & $20516(42.0)$ & $7032(55.8)$ & $13484(37.2)$ & \\
\hline Hospital-outpatient & $28294(58.0)$ & $5579(44.2)$ & $22715(62.8)$ & \\
\hline Treatment type & & & & $<0.001$ \\
\hline Conventional external beam & $40265(82.5)$ & $11013(87.3)$ & $29252(80.8)$ & \\
\hline IMRT & $3916(8.0)$ & $1543(12.2)$ & $2373(6.6)$ & \\
\hline Other & $1397(2.9)$ & $40(0.3)$ & $1357(3.7)$ & \\
\hline SRS/SBRT & $3232(6.6)$ & $15(0.1)$ & 3217 (8.9) & \\
\hline Age group & & & & $<0.001$ \\
\hline$<65$ & $5672(11.6)$ & $1465(11.6)$ & 4207 (11.6) & \\
\hline $65-74$ & $22469(46.0)$ & $5981(47.4)$ & $16488(45.5)$ & \\
\hline $75-84$ & $15677(32.1)$ & $4020(31.9)$ & $11657(32.2)$ & \\
\hline $85+$ & $4992(10.2)$ & $1145(9.1)$ & $3847(10.6)$ & \\
\hline Sex & & & & 0.06 \\
\hline Male & $27115(55.6)$ & $6915(54.8)$ & $20200(55.8)$ & \\
\hline Female & $21695(44.4)$ & $5696(45.2)$ & $15999(44.2)$ & \\
\hline Major procedure & & & & 0.29 \\
\hline No & $34014(69.7)$ & $8836(70.1)$ & $25178(69.6)$ & \\
\hline Yes & $14796(30.3)$ & $3775(29.9)$ & $11021(30.4)$ & \\
\hline Chemotherapy & & & & $<0.001$ \\
\hline No & $12246(25.1)$ & $2886(22.9)$ & $9360(25.9)$ & \\
\hline Yes & $36564(74.9)$ & $9725(77.1)$ & $26839(74.1)$ & \\
\hline Overall death during episode & & & & $<0.001$ \\
\hline No & $38854(79.6)$ & $10943(86.8)$ & $27911(77.1)$ & \\
\hline Yes & $9956(20.4)$ & $1668(13.2)$ & $8288(22.9)$ & \\
\hline
\end{tabular}

${ }^{*} \chi 2$.

IMRT, intensity modulated radiation therapy; SRS/SBRT, stereotactic radiosurgery/stereotactic body radiotherapy.

\section{RESULTS}

There were 48810 episodes for bone metastases during the period, of which $28294(58 \%)$ occurred in the hospital-outpatient setting (table 1). Patients were primarily in the age groups $65-74(\mathrm{~N}=22469 ; 46.0 \%)$ and $75-84(15,677 ; 32.1 \%)$ and were male $(\mathrm{N}=27115$; $55.6 \%)$. About one-third underwent a major procedure $(\mathrm{N}=14796 ; 30.3 \%)$ and a three-quarters received chemotherapy ( $\mathrm{N}=36564 ; 74.9 \%$ ) within the 90 days prior to the episode. Overall, $74 \%$ of episodes were for receipt of $\leq 10$ fractions (13484 of $20516(66 \%)$ received $\leq 10$ fractions in free-standing centres, compared with 22715 of 28294 $(80 \%)$ in hospital-outpatient centres). When evaluating episodes by receipt of $\leq 10$ fractions, $37.2 \%$ ( $\mathrm{N}=13484)$ of episodes for $\leq 10$ fractions occurred in free-standing centres, compared with $62.8 \%(\mathrm{~N}=22715)$ in hospital outpatient settings, $\mathrm{p}<0.001$.

Unadjusted and adjusted estimates of analysis of receipt of 10 or fewer fractions of radiation for bone metastases are shown in table 2. After adjusting for treatment and patient factors, hospital-outpatient treatment setting remained a significant predictor of receiving $\leq 10$ fractions (adjusted OR 2.12 (95\% CI 2.04, 2.21; p<0.001) compared with free-standing).

Unadjusted and adjusted estimates of expenditures associated with receipt of 10 or fewer fractions of radiation for bone metastases are shown in table 3. After adjusting for patient factors, the primary factors contributing to total expenditures were number of fractions (US\$-3424 $(95 \%$ CI US $\$-3412$ to US $\$-3435)$ for $\leq 10$ fractions vs $>10$; $\mathrm{p}<0.001$ ) and treatment type (including US $\$ 7716$ (95\% CI US $\$ 7424$ to US\$8018) for IMRT compared with conventional external beam; $\mathrm{p}<0.001$ ), with smaller estimated effects for treatment setting (US $\$ 110$ (95\% CI US $\$ 55$ to US\$168) for hospital-outpatient vs free-standing; $\mathrm{p}<0.001$ ), age (US\$-226 (95\% CI US\$-331 to -US\$116), for age $85+$ vs $<65 ; \mathrm{p}<0.001$ ), chemotherapy (US $\$ 179$ (95\% CIUS $\$ 114$ to US $\$ 246)$; $\mathrm{p}<0.001$ ), major procedure 
Table 2 Unadjusted and adjusted analysis of receipt of 10 or fewer fractions of radiation for bone metastases

\begin{tabular}{|c|c|c|c|c|}
\hline & $\begin{array}{l}\text { Unadjusted OR for receipt of } \\
\leq 10 \text { fractions }(95 \% \mathrm{Cl})\end{array}$ & P value* & $\begin{array}{l}\text { Adjusted OR for receipt of } \\
\leq 10 \text { fractions }(95 \% \mathrm{Cl})\end{array}$ & P value* \\
\hline Overall & -- & -- & 2.09 (1.93 to 2.26$)$ & $<0.001$ \\
\hline Freestanding & 1.00 & & 1.00 & \\
\hline Hospital-outpatient & 2.12 (2.04 to 2.21 ) & $<0.001$ & 2.12 (2.04 to 2.21$)$ & $<0.001$ \\
\hline \multicolumn{5}{|l|}{ Age group } \\
\hline $65-74$ & 0.96 (0.90 to 1.03$)$ & 0.23 & 0.98 (0.92 to 1.05$)$ & 0.60 \\
\hline $75-84$ & 1.01 (0.94 to 1.08$)$ & 0.78 & 1.04 (0.97 to 1.12$)$ & 0.26 \\
\hline $85+$ & 1.17 (1.07 to 1.28$)$ & $<0.001$ & 1.20 (1.10 to 1.32$)$ & $<0.001$ \\
\hline \multicolumn{5}{|l|}{ Sex } \\
\hline No & 1.00 & & 1.00 & \\
\hline Yes & 1.03 (0.98 to 1.07 ) & 0.28 & 1.02 (0.98 to 1.07 ) & 0.35 \\
\hline \multicolumn{5}{|l|}{ Chemotherapy } \\
\hline No & 1.00 & & 1.00 & \\
\hline Yes & 0.85 (0.81 to 0.89$)$ & $<0.001$ & 0.88 (0.84 to 0.93$)$ & $<0.001$ \\
\hline
\end{tabular}

*Logistic regression model.

$\mathrm{Cl}$, confidence interval; IMRT, intensity modulated radiation therapy; OR, odds ratio; SRS/SBRT, stereotactic radiosurgery/stereotactic body radiotherapy.

(US\$71 (95\% CI US\$13 to US $\$ 131) ; p=0.02)$ and death during the episode (US\$-815 (95\% CI -US\$863 to US\$765); $\mathrm{p}<0.001)$.

\section{DISCUSSION}

Delivery of higher-value radiation for bone metastases differs by treatment setting

Delivery of higher-value radiation for bone metastases differs by treatment setting in this nationwide sample of RO Model-defined episodes, with lower short course utilisation and higher IMRT utilisation in free-standing centres associated with higher expenditures. As compared with prior analyses of bone metastases using CMS data, ${ }^{15-18}$ these data provide distinct and recent data on CMS-defined episodes of care. These findings are similar to Logan et $a l^{5}$ who evaluated trends in fractionation and cost of bone metastasis radiation from 2011 to 2014 with $79.9 \%$ receiving 10 or fewer fractions in 2014 and demonstrating increased use in patients with advanced age. While we did not evaluate trends, our data likely represent a continuation of this trend, and validate the persistent performance gap using CMS episode criteria for the RO Model. We also found that the proportion of patients receiving short ( $\leq 10$ fraction) courses of radiation in the hospital-outpatient setting are slightly lower than those reported using a quality measure approach with the limited 2018 reporting in Hospital Compare $(80 \%$ vs $89 \%$, respectively), though Hospital Compare likely selects for hospitals that performed well on the measure due to the ability to select reported measures. While the value of such short courses has been shown to be greater in appropriate patients, the inability to differentiate in this dataset between those who may benefit from specific regimens such as SRS, SBRT or IMRT, which are associated with higher costs but may be appropriate in select patients, such as certain patients with painful spinal metastases ${ }^{19}$ or oligometastatic disease, ${ }^{20}$ may also represent a limitation of the RO Model that should be investigated further to ensure flexibility for optimising individualised outcomes. We also validate single-institutional findings of differences in cost by treatment regimen for $<10$ fractions in a 90 -day episode, ${ }^{21}$ though our cost values were lower.

\section{Potential impacts of the $\mathrm{RO}$ Model on palliative radiation of bone metastases}

Given that the RO Model is site-neutral and modality agnostic, these findings suggest that the impact of the RO Model on palliative radiation of bone metastases will likely be greatest in free-standing centres and confirms the potential of the episode-based approach of the RO Model to improve value and provide cost savings for palliative radiation of bone metastases. It is not yet clear if these findings can be translated to treatment of other cancer types. It is possible that certain cancer types such as prostate cancer may provide another example of the potential 
Table 3 Unadjusted and adjusted analysis of expenditures associated with receipt of 10 or fewer fractions of radiation for bone metastases

\begin{tabular}{|c|c|c|c|c|}
\hline Covariable & Unadjusted mean difference $(95 \% \mathrm{Cl})$ & P value* & Adjusted mean difference $(95 \% \mathrm{Cl})$ & $P$ value \\
\hline \multicolumn{5}{|l|}{ No of fractions } \\
\hline$>10$ & ref & & ref & \\
\hline$\leq 10$ & -US\$3070 (-3112 to -3027$)$ & $<0.001$ & -US\$3424 (-3412 to -3435$)$ & $<0.001$ \\
\hline \multicolumn{5}{|l|}{ Treatment setting } \\
\hline Freestanding & ref & & ref & \\
\hline Hospital-outpatient & - US\$457 (-526 to -387$)$ & $<0.001$ & US\$110 (55 to 168$)$ & $<0.001$ \\
\hline \multicolumn{5}{|l|}{ Treatment type } \\
\hline $\begin{array}{l}\text { Conventional external } \\
\text { beam }\end{array}$ & ref & & ref & \\
\hline IMRT & US $\$ 6032$ (5833 to 6235) & $<0.001$ & US $\$ 7716$ (7424 to 8018$)$ & $<0.001$ \\
\hline Other & US\$11917 (11111 to 12776$)$ & $<0.001$ & US\$20220 (19401 to 21073 ) & $<0.001$ \\
\hline SRS/SBRT & US\$6522 (6112 to 6956) & $<0.001$ & US\$11845 (11422 to 12283$)$ & $<0.001$ \\
\hline \multicolumn{5}{|l|}{ Age group } \\
\hline$<65$ & ref & & ref & \\
\hline $65-74$ & US\$114 (-11 to 245$)$ & 0.07 & US\$151 (63 to 243$)$ & 0.001 \\
\hline $75-84$ & - US\$259 (-377 to -136$)$ & $<0.001$ & -US\$10 (-99 to 81$)$ & 0.82 \\
\hline $85+$ & -US\$793 (-921 to -658$)$ & $<0.001$ & -US\$226 (-331 to -116$)$ & $<0.001$ \\
\hline \multicolumn{5}{|l|}{ Sex } \\
\hline Male & ref & & & \\
\hline Female & US $\$ 35$ ( -40 to 111$)$ & 0.36 & - US\$18 ( -70 to 36$)$ & 0.50 \\
\hline \multicolumn{5}{|l|}{ Major procedure } \\
\hline No & ref & & ref & \\
\hline Yes & US\$470 (384 to 559$)$ & $<0.001$ & US $\$ 71$ (13 to 131$)$ & 0.02 \\
\hline \multicolumn{5}{|l|}{ Chemotherapy } \\
\hline No & ref & & ref & \\
\hline Yes & US\$174 (87 to 264) & $<0.001$ & US\$179 (114 to 246$)$ & $<0.001$ \\
\hline \multicolumn{5}{|l|}{ Death during episode } \\
\hline No & ref & & ref & \\
\hline Yes & -US\$1652 (-1715 to -1587$)$ & $<0.001$ & -US\$815 (-863 to -765$)$ & $<0.001$ \\
\hline
\end{tabular}

${ }^{*}$ Generalised linear model (gamma distribution with log link).

†Generalised linear model (gamma distribution with log link). Overall mean: US $\$ 8143$ (95\% CI US $\$ 8031$ to US $\$ 8258), p<0.001$.

IMRT, intensity modulated radiation therapy; SRS/SBRT, stereotactic radiosurgery/stereotactic body radiotherapy.

for improving value through integrating individualised care. ${ }^{22}$ Providing resources to free-standing centres to develop and invest in the sustainability of palliative radiation programmes may help to facilitate successful RO Model participation, while incorporation of new data supporting advanced techniques is needed to ensure the model provides high-value care and optimal outcomes for individual patients. Emerging data support the use of SRS/SBRT to improve patient outcomes in select patients with bone metastases and may require re-evaluation of the RO Model to ensure that patients receive optimal value-based care. ${ }^{19} 2023$

\section{Study limitations}

Our study is limited by the available data in the RO Model episode file, which does not include important patient characteristics such as performance status, prior radiation, presence of other metastases or site of radiation. However, the inclusion of patient characteristics such as age, receipt of a procedure or chemotherapy and death during the episode does account for casemix variation. ${ }^{13}$ In addition, our findings are similar to other analyses showing ongoing use of more complex or longer courses of radiation in addition to greater use of longer courses in free-standing centres. ${ }^{24-26}$ This suggests that the episode-based approach may capture the value of radiotherapy for bone metastases, though further exploration using patient-level data is needed and will be part of the ongoing evaluation of the programme. ${ }^{13}$ In addition, our findings may not be generalisable to patients who are not Medicare fee-for-service beneficiaries, including 
many younger patients or patients who are not otherwise eligible for Medicare.

In conclusion, a measurable performance gap exists for the delivery of higher-value bone metastases radiotherapy under an episode-based model, associated with increased expenditures. The RO Model may succeed in improving the value of bone metastases radiation for Medicare beneficiaries. Increasing the capacity of free-standing centres to implement palliative-focused services may improve the ability of these practices to succeed under the RO Model.

Contributors Study concept and design: DM. Acquisition, analysis or interpretation of data: DM, MDA and KD. Drafting of the manuscript: DM. Critical revision of the manuscript for important intellectual content: DM, MDA and KD. Final approval of the version to be published: DM, MDA and KD. Agreement to be accountable for all aspects of the work: DM, MDA and KD. Overall content guarantor: DM.

Funding DM contribution to this project was supported in part by the National Institutes of Health/National Cancer Institute (T32 CA225617).

Competing interests None declared.

Patient and public involvement Patients and/or the public were not involved in the design, or conduct, or reporting, or dissemination plans of this research.

Patient consent for publication Not applicable.

Ethics approval This study was did not meet the definition of human subjects research therefore did not require human subjects ethics review.

Provenance and peer review Not commissioned; externally peer reviewed.

Data availability statement Data are available in a public, open access repository. Research data are available at: https://innovation.cms.gov/innovation-models/ radiation-oncology-model.

Open access This is an open access article distributed in accordance with the Creative Commons Attribution Non Commercial (CC BY-NC 4.0) license, which permits others to distribute, remix, adapt, build upon this work non-commercially, and license their derivative works on different terms, provided the original work is properly cited, appropriate credit is given, any changes made indicated, and the use is non-commercial. See: http://creativecommons.org/licenses/by-nc/4.0/.

ORCID iD

Deborah Marshall http://orcid.org/0000-0002-6675-7482

\section{REFERENCES}

1 Centers for Medicare \& Medicaid Services (CMS), HHS. Medicare Program; Specialty Care Models To Improve Quality of Care and Reduce Expenditures, 2020.

2 United States Department of Health and Human Services. Report to Congress: Episodic Alternative Payment Model for Radiation Therapy Services, 2017. Available: https://innovation.cms.gov/files/reports/ radiationtherapy-apm-rtc.pdf

3 Sze WM, Shelley M, Held I, et al. Palliation of metastatic bone pain: single fraction versus multifraction radiotherapy - a systematic review of the randomised trials. Cochrane Database Syst Rev 2004;2002:CD004721.

4 Chow E, Zeng L, Salvo N, et al. Update on the systematic review of palliative radiotherapy trials for bone metastases. Clin Oncol 2012;24:112-24.

5 Chow R, Hoskin P, Chan S, et al. Efficacy of multiple fraction conventional radiation therapy for painful uncomplicated bone metastases: A systematic review. Radiother Oncol 2017;122:323-31.
6 Lutz S, Balboni T, Jones J, et al. Palliative radiation therapy for bone metastases: Update of an ASTRO Evidence-Based Guideline. Pract Radiat Oncol 2017;7:4-12.

7 Chow R, Hoskin P, Schild SE, et al. Single vs multiple fraction palliative radiation therapy for bone metastases: Cumulative metaanalysis. Radiother Oncol 2019;141:56-61.

8 Hartsell WF, Scott CB, Bruner DW, et al. Randomized trial of shortversus long-course radiotherapy for palliation of painful bone metastases. J Natl Cancer Inst 2005;97:798-804.

9 National Quality Forum. External Beam Radiotherapy for Bone Metastases, 1822.

10 ASTRO. Letter: 2019 Hospital Outpatient Prospective Payment System Proposed Rule, 2019. Available: https://www.astro.org/ ASTRO/media/ASTRO/Daily Practice/PDFs/2019HOPPSPropose dRuleComments.pdf [Accessed 10 Feb 2020].

11 Centers for Medicare and Medicaid Services. Timely and Effective Care - National Hospital Compare Dataset, 2020. Available: https:// data.medicare.gov/Hospital-Compare/Timely-and-Effective-CareNational/isrn-hqyy/data [Accessed 10 Feb 2020].

12 Chang S, May P, Goldstein NE, et al. A Palliative Radiation Oncology Consult Service's Impact on Care of Advanced Cancer Patients. J Palliat Med 2018;21:438-44.

13 Centers for Medicare and Medicaid Services,. Radiation Oncology Alternative Payment Model Proposed Rule. Available: https://www. hhs.gov/sites/default/files/CMS-5527-P.pdf [Accessed 1 Sep 2019].

14 Centers for Medicare and Medicaid Services. Radiation Oncology Alternative Payment Model Episode File and Data Dictionary, 2020. Available: https://innovation.cms.gov/initiatives/radiation-oncologymodel/ [Accessed 1 Feb 2020].

15 Logan JK, Jiang J, Shih Y-CT, Tina Shih YC, et al. Trends in radiation for bone metastasis during a period of multiple national quality improvement initiatives. J Oncol Pract 2019;15:e356-68.

$16 \mathrm{Yu}$ JB, Pollack CE, Herrin J, et al. Persistent use of extended fractionation palliative radiotherapy for medicare beneficiaries with metastatic breast cancer, 2011 to 2014. Am J Clin Oncol 2019;42:493-9.

17 Bekelman JE, Epstein AJ, Emanuel EJ. Single- vs multiple-fraction radiotherapy for bone metastases from prostate cancer. JAMA 2013;310:1501.

18 Robinson TJ, Dinan MA, Li Y, et al. Longitudinal trends in costs of palliative radiation for metastatic prostate cancer. $J$ Palliat Med 2015;18:933-9.

19 Sahgal A, Myrehaug SD, Siva S, et al. CCTG SC.24/TROG 17.06: A Randomized Phase II/III Study Comparing 24Gy in 2 Stereotactic Body Radiotherapy (SBRT) Fractions Versus 20Gy in 5 Conventional Palliative Radiotherapy (CRT) Fractions for Patients with Painful Spinal Metastases. Int J Radiat Oncol Biol Phys 2020;108:1397-8.

20 Palma DA, Olson R, Harrow S, et al. Stereotactic Ablative Radiotherapy for the Comprehensive Treatment of Oligometastatic Cancers: Long-Term Results of the SABR-COMET Phase II Randomized Trial. JCO 2020;38:2830-8.

21 Waddle MR, Kaleem T, Stross WC, et al. The cost implications of palliative radiation therapy dose and fractionation for painful metastatic bone lesions. JCO 2018;36:145.

22 Kucera R, Pecen L, Topolcan O, et al. Prostate cancer management: long-term beliefs, epidemic developments in the early twenty-first century and 3PM dimensional solutions. Epma J 2020;11:399-418.

23 Palma DA, Salama JK, Lo SS, et al. The oligometastatic state - separating truth from wishful thinking. Nat Rev Clin Oncol 2014;11:549-57.

24 Spratt DE, Mancini BR, Hayman JA, et al. Contemporary Statewide Practice Pattern Assessment of the Palliative Treatment of Bone Metastasis. Int J Radiat Oncol Biol Phys 2018;101:462-7.

25 Stevens R, Macbeth F, Toy E, et al. Palliative radiotherapy regimens for patients with thoracic symptoms from non-small cell lung cancer. Cochrane Database Syst Rev 2015;1:CD002143.

26 Wallace AS, Fiveash JB, Williams CP, et al. Choosing Wisely at the End of Life: Use of Shorter Courses of Palliative Radiation Therapy for Bone Metastasis. Int J Radiat Oncol Biol Phys 2018;102:320-4. 